\title{
Bioaccumulation of Vanadium in Selected Organs of the Freshwater Fish Heteropneustes fossilis (Bloch)
}

\author{
Ambili Ravindran* and M. V. Radhakrishnan**† \\ *Research \& Development Centre, Bharathiar University, Coimbatore-641 046, Tamilnadu, India \\ **Department of Zoology, Chikkanna Government Arts College, Tirupur-641 602, Tamilnadu, India \\ †Corresponding author: M. V. Radhakrishnan; mvrkrishnan44@yahoo.com
}

Nat. Env. \& Poll. Tech. Website: www.neptjournal.com

Received: 29-09-2019

Revised: 11-11-2019

Accepted: 11-12-2019

Key Words:

Bioaccumulation

Vanadium

Toxicity
Heteropneustes fossilis

\begin{abstract}
Extensive industrialization and urbanization have introduced domestic as well as industrial wastes into aquatic ecosystems.Dueto lack of proper treatment and improper mode of disposal, the water bodies have become more polluted with toxic substancesand their adverse effects including mortality to aquatic organisms, are becoming more prominent.In recent years, much attention has been paid to the possible danger of metal poisoning in humans as a result of consumption of contaminated fishes. Vanadium is a rare elementfound combined with certain minerals and mainly from the production of certain alloys used in jet engines. Humans may be exposed to excessive vanadium and may develop adverse vascular effects. In the present investigation, efforts have been made to investigate the effect of sublethal concentration of vanadium $\left(6.5 \mathrm{ppm} ; 10 \%\right.$ of $\left.96 \mathrm{~h} \mathrm{LC}_{50}\right)$ on the bioaccumulation in gill, liver and skin of the catfish Heteropneustes fossilis for 60 days. The pattern of bioaccumulation was in the order liver > gill > skin. Theresults suggest that the organ-specific variation is directly related to the structural and functional change, proximity to the toxicant and presence of ligands having high affinity to vanadium.
\end{abstract}

\section{INTRODUCTION}

In India, even though industrialization has not reached the level attained in the developed countries, pollution of aquatic habitats seems to be an inevitable problem. More toxic compounds are being increasingly detected in aquatic ecosystems. With the advent of the agricultural and industrial revolution, most of the water sources are becoming contaminated with diverse pollutants (Khare \& Singh 2002). Industrial discharges containing toxic and hazardous substances, including heavy metals, contribute significantly to the pollution of aquatic ecosystems(Gbem et al. 2001, Woodling et al. 2001). According to Satyanarayanan et al.(1985), the presence of heavy metals on the east coast of India deserves special mention as it almost forms a repository for industrial effluents and city sewage. Among the various heavy metals, in general, vanadium is a biologically non-essential, non-biodegradable, persistent type of heavy metal and its compounds are known to have high toxic potentials. Further, continuous, low-level vanadium exposure may have a gross biological impact comparable to that of recurring exposures of much greater intensity. In freshwater fish, metal uptake is taking place mainly through three routes namely, gills, skin and also from food via the intestinal wall (Karlsson-Norrgran \& Runn 1985). On the other hand, the metal retention capacity of fishes is dependent on their metal assimilation and excretion capabilities (Rao \& Patnaik 1999). According to Ferardet al.(1983),aquatic organisms take up heavy metals and concentrate them to amounts considerably higher than those found in the environment. Therefore, it is important to find the pathways of accumulation of heavy metals and their affinity to different tissues, especially in fishes. In this context, the present investigation has been designed to study the pattern of bioaccumulation of vanadium in the gills, liver and skin of the catfish Heteropneustes fossilis(Bloch.) exposed to sublethal concentrations of vanadium.

\section{MATERIALS AND METHODS}

Collection and maintenance of fish:The freshwater fish Heteropneustes fossilis ( $12 \pm 2 \mathrm{~cm}$ length and $34 \pm 2 \mathrm{~g}$ weight) were collected locally, brought to the laboratory and kept in a tank with size $60 \times 30 \times 30(1 \times b \times h) \mathrm{cm}$, filled with tap water for acclimatization for about two weeks. During the acclimatization, the fish were fed with minced goat liver on every alternate day. Water in the tank was renewed, three or four times in a week and aerated to ensure sufficient oxygen supply. For the fish used in the experiment, feeding was stopped two days before the start of the experiment to reduce the quantum of excretory products in the tank. 
Estimation of $\mathbf{L C}_{\mathbf{5 0}}$ : Before the commencement of the experiment, 96h $\mathrm{LC}_{50}$ value was determined using trimmed spearman Karber method (Hamilton et al. 1977)which was found to be $65 \mathrm{ppm}$ after $95 \%$ trimming.

Experimental protocol:For the analysis of sublethal toxicity six groups of 10 fish each were exposed separately to vanadium $\left(6.5 \mathrm{ppm} ; 10 \%\right.$ of $\left.96 \mathrm{~h} \mathrm{LC}_{50}\right)$ solution prepared in tap water. The experimental medium was prepared by dissolving vanadium $(6.5 \mathrm{ppm})$ in tap water having dissolved oxygen $6 \mathrm{ppm}$, pH 7.5, water hardness $40.44 \mathrm{mg} / \mathrm{L}$ and water temperature $28 \pm 2^{\circ} \mathrm{C}$ (APHA 2008). Each group was exposed to $50 \mathrm{~L}$ of the experimental medium. Parallel groups of 10 fish each were kept in separate aquaria containing $50 \mathrm{~L}$ tap water without the addition of vanadium as control. Feeding was allowed in the experimental as well as control groups every day for a period of $3 \mathrm{~h}$ before the renewal of the media throughout the tenure of the experiment.After the expiry of $5,10,20,30,40$ and 60 days of exposure five fish each from the respective experimental as well as control groups were sacrificed and bioaccumulation of vanadium was found.

Estimation of vanadium:For the analyses, the gill, fragments of the liver and a part of the skin on the dorsal surface of each fish were dissected, washed with distilled water and weighed following FAO methods (2006). The separated organs were driedat $120^{\circ} \mathrm{C}$ in Petri dishes until reaching a constant weight. The separated organs were placed in digestion flasks and ultra-pure concentrated nitric acid and hydrogen peroxide $(1: 1 \mathrm{v} / \mathrm{v})$ were added. The digestionflasks were then heated to $130^{\circ} \mathrm{C}$ until all the materials were dissolved. Digest was diluted with double distilledwater appropriately and vanadium was assayed. Atomic absorption spectrophotometer (Perkin Elmer) using element-specific hollow cathode lamp in default condition, by flame absorption mode was used to approximate the metal concentration (Kendall \& Scanlon 1982). The metal standard recommended by Perkin Elmer was used for checking the sensitivity of the instrument and calibration.

The data obtained were subjected to standard statistical analysis each sampling time and their respective control groups in different groups. Duncan's multiple range test (Bruning \& Kintz 1968) was performed to determine whether the parameters altered significantly by exposure periods.

\section{RESULTS}

Gill: Of all the tissues investigated, the rate of accumulation of vanadium was maximum ingills of the exposed fish.No detectable amount of vanadium was observed in the gills of the control fish. The gill registered $1.92 \pm 0.02,0.98 \pm 0.05$, $0.85 \pm 0.01,0.71 \pm 0.02$ and $1.18 \pm 0.01 \mathrm{ppm}$ of vanadium for $5,10,20,30$ and 60 days of exposure to sublethal concentration of vanadium solution (Fig. 1). After an initial surge, the metal concentration decreased gradually until the

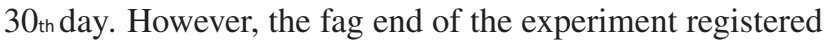
an increasing trend in the accumulation pattern.

Skin: Even though skin constitutes the single tissue having maximum surface area and direct contact with the toxicant medium, the rate of accumulation was less when compared to other tissues, such as gills and liver (Fig. 1).No vanadium was traceable in the skin of the control fish. The skin recorded $0.35 \pm 0.01,0.48 \pm 0.01,0.25 \pm 0.01,0.18 \pm 0.01$ and 0.15 $\pm 0.00 \mathrm{ppm}$ of vanadium for $5,10,20,30$ and 60 days of exposure to sublethal concentration of vanadium solution (Fig. 1).In the case of the experimental fish, the rate of accumulation decreased during the later periods, leading to an overall decrease in the rate of bioaccumulation of vanadium in the skin tissue.

Liver: As with the case of gills, vanadium could not be traced in the liver of the control fish. In the case of the experimental groups, even though the quantity of accumulated vanadium was less in case of the liver when compared to gills, the pattern of accumulation showed a more or less continuous increasing trend at all the periods of exposure. The liver recorded $0.71 \pm 0.02,0.84 \pm 0.02,0.96 \pm 0.01$, $1.12 \pm 0.01$ and $1.26 \pm 0.02 \mathrm{ppm}$ of vanadium for $5,10,20$, 30 and 60 days of exposure to sublethal concentration of vanadium solution (Fig. 1).

\section{DISCUSSION}

The exposure of $H$. fossilis to sublethal concentration of vanadium caused significant accumulation in the organs and the accumulation was associated with the duration of exposure in different tissues. The rate of accumulation was in the order gill $>$ liver $>$ skin and it may be inferred that the pattern of accumulation of vanadium differs from tissue to tissue. The critical analysis revealed that the rate of accumulation in the various tissues in comparison to their respective controls is influenced by the duration of exposure. However, there occurred significant variations in the concentration of accumulated vanadium in the various tissues studied at different exposure periods when compared with the respective preceding exposure periods. This difference in accumulation may be attributed to the proximity of the tissue to the toxicant medium, the physiological state of the tissue, presence of ligands having an affinity to vanadium and/or to the role of the tissue in the detoxification process.

From the point of view of proximity to toxicant of the various tissues analysed, gills and skin are in direct contact with the toxic medium, whereas liver is exposed through 


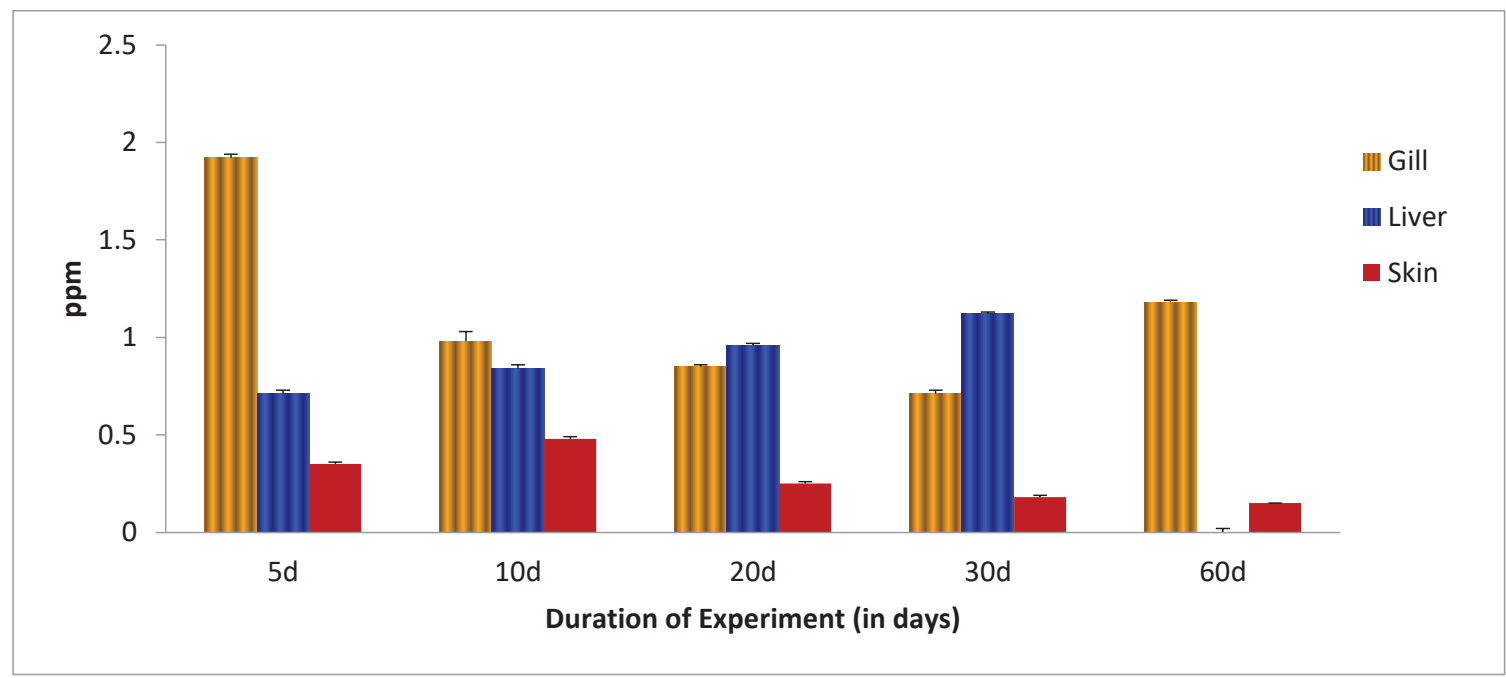

Fig. 1: Bioaccumulation of vanadium (ppm) in gill, liver and skin of $H$. fossilisin different experimental groups after 5, 10, 20, 30 and 60 days of sublethal exposure.

media effect. Even though the gills and skin come into direct contact with the ambient toxicant, the pattern of bioaccumulation showed considerable differences between them. While gill was the organ accumulating the maximum vanadium, skin accumulated a far lower amount. Even though reports indicate a correlation between bioaccumulation of metals and exposure concentration, along with exposure time (Giles 1988), such a correlation did not exactly seem to fit data from the present study, as both skin and gill are faced with the same concentration of the toxicant and the same exposure period. A probable reason for the observed difference in the metal accumulating capacity of gills and skin may be the physiological state of the tissue and/or structural and functional organization of these organs. In the case of fish and crustaceans, as well as molluscs, gills are one of the target organs to suffer instantaneously from ambient toxicants. One of the basic reasons for the gills to act as the primary site for cadmium accumulation, as observed in the present study, is its external position and its proximity to the ambient toxicants. In addition, the highly branched structural organization of the gill and the resultant highly increased surface area, along with the large volume of water passing through the gill surface and the highly vascular physiological state and the relatively small biomass when compared to their surface area (Mayer et al. 1991) make the gill a prime site for vanadium accumulation.

As far as the presence of various ligands in the tissues is concerned, being an oxyphilic and sulphophilic element, vanadium undergoes multiple bondings in the body (Moore \&Ramamoorthy 1984), forming stable complexes with a variety of organic compounds. In the present study, the increased mucogenesis under the influence of toxicant, as also reported by Rajan\& Banerjee (1991), might result in the formation of a mucous trap over the gills for the vanadium ions due to the preferential attraction of cadmium to the -SH groups present in the mucus. The cation binding capacity of the fish mucus is also reported by Ingerssolet al. (1990). However, according to Paul \& Banerjee (1997), due to the constant and increased ventilatory movements of the operculum under the influence of the xenobiotics, the protective mucous plug inside the opercular chamber is quite often discharged into the medium. Such discharges of the mucous plug might make the gills a more vulnerable site for the accumulation of vanadium. All these structural and functional peculiarities of the gills, along with the high vascularization, might be responsible for the highest rate of accumulation of vanadium. On the contrary, the skin, which also comes under the direct contact stress of the toxicant, shows a far lesser rate of bioaccumulation. According to Rajan\& Banerjee (1991) and Paul \& Banerjee (1996), the mucogenic activity of the body skin epithelium in fish is very high when compared to gills (Hemalatha\& Banerjee 1997). This increased mucogenesis may play a crucial role in preventing the vanadium ions from entering the body, as the coagulated mucus all over the body might be acting as a protective ion trap. Further, unlike gill, discharge of the body mucus into the medium is not an active process as there are no ventilatory movements in the skin epithelium, and the rejected epithelial cells, along with the proteinaceous contents of the other degenerating cells, form a protective 
scab over the skin. Such a protective covering may act as an efficient trap for the metal ions and, at a later stage, when the cellular debris along with the mucous mass is released into the medium, the entire accumulated vanadium ions might be rejected into the medium itself and thereby greatly retard their entry into the body skin. Moreover, the regeneration of the exhausted and sloughed mucous cells is quite quick in the case of body skin when compared to the opercular epithelium (Paul \& Banerjee 1996, 1997) and gills (Hemalatha\& Banerjee 1997), leaving less time for the accumulation of vanadium on the body skin epithelium. The intermittent increases observed in the concentration of vanadium in skin and gill at various stages of exposure may be attributed, at least partially, to the temporary breakdown of the mucogenic barrier due to the exhaustion of the mucous cells after their hyperactivity.

Even though the liver did not come into direct contact with the medium, the vanadium accumulation pattern followed more or less the same pattern as that of gills. Many other workers have also reported the increased metal accumulation capacities in liver and gills of aquatic organisms (Protasowicki\&Chodyniecki 1992, Narayanan et al. 1997). One of the main reasons attributed to the increased presence of heavy metals in these organs is their capacity to accumulate vanadium brought by blood from other parts of the body and induce the production of the metal-binding protein, metallothionein, which is believed to play a crucial role against the toxic effects of heavy metals by binding them (Bhattacharya et al. 1985). According to Klavercampet al. (1984), the gill and the liver are the main sites of metallothionein production and metal retention. This may be yet another main reason for the enhanced presence of vanadium in the gills, skin and liver. Also, all these tissues are rich in the metal binding-SH groups (Rema \& Philip 1997) and therefore it is not surprising that the metal ions are complexed in these organs. According to Kent (1998), the liver is involved in the detoxification of toxic substances circulating in the bloodstream. Moreover, liver, being the major organ of metabolic activities including detoxification (Klavercampet al. 1984), vanadium might also be transported into this from other tissues, including gills and skin, for subsequent elimination. Such transportation might lead to higher rates of accumulation in the liver. The possibility of such detoxification related mobilization of accumulated vanadium may be one reason for the intermittent reduction in the quantity of accumulated vanadium in gills, as well as the skin at various stages of exposure.

\section{CONCLUSION}

The pattern of bioaccumulation in Heteropneustes fossilis after sublethal vanadium treatment clearly shows that heavy metals, whatever the concentration, are quite unbiological and caution should be exercised in allowing vanadium into the aquatic environment. By knowing the mechanism of the specific toxic action of poisons, it is possible to use various pharmacological compounds to reduce the toxic effect of pollutants. Further, the toxic effect of metals in organisms in contaminated water is an important aspect of environmental awareness, because it may affect all members of the food chain. Moreover, management of our water bodies is required if they are to be used for diverse purposes as domestic and industrial supply, crop irrigation, sports and commercial fisheries, power generation, etc.

\section{REFERENCES}

APHA 2008. Standard Methods for Examination of Water and Wastewater.19th ed. American Public Health Association, Washington DC.

Bhattacharya, T., Ray,A.K. and Bhattacharya, S. 1985. Response of Channapunctatus under short term and long term exposure to industrial pollutants: Induction of histopathology in the kidney. Z. Mikrosk. Anat. Forsch (Leipz), 899: 327-334.

Bruning, J.L. and Kintz, B.L. 1968. Computational Handbook of Statistics. Foresman and Company, Dallas, USA, p. 308.

FAO 2006. State of World Aquaculture 2006. FAO Fisheries Technical Paper, 500:134.

Ferard, J.F., Jouany,J.M.,Truhaut,R. andVasseur, P. 1983. Accumulation of cadmium in a freshwater food chain experimental model. Ecotoxicol. Environ. Safe., 7: 43-52.

Gbem, T.T., Balogun,J.K., Lawal,F.A. andAnnune, P.A. 2001. Trace metal accumulation in Clariasgariepinus exposed to sublethal levels of tannery effluent. Sci. Total. Environ., 271: 1-9.

Giles, M.A. 1988. Accumulation of cadmium by rainbow trout, Salmogairdneri, during extended exposure. Can. J. Fish. Acquat. Sci., 45: 1045-1053.

Hamilton, M.A., Russo, R.C. and Thurston, R.V. 1977. Trimmed Spearman Karber method for estimating median lethal concentrations in toxicity bioassays. Environ. Sci. Tech., 11: 714-719.

Hemalatha, S. and Banerjee, T.K. 1997. Histopathological analysis of acute toxicity of zinc chloride on the respiratory organs of air breathing catfish Heteropneustes (Saccobranchus) fossilis (Bloch.).Vet. Archiv.,67(1): 11-24.

Ingerssol, C.G., Saches,D.A., Meyer,J.S.,Gutley,D.D. andTietige, J.E. 1990. Epidermal response to $\mathrm{pH}$, aluminium and cadmium exposure in brook trout (Salveniusfontinales) fry. Can. J. Fish. Aquat. Sci., 47: 1616-1622.

Karlsson-Norrgren, L. and Runn, P. 1985. Cadmium dynamics in fish: Pulse studies with ${ }^{109} \mathrm{Cd}$ in female Zebrafish, Brachydaniorerio. J. Fish. Biol., 27: 571-581.

Kendall, R.J. and Scanlon, P.F. 1982. A rapid method for analysis of tissues for heavy metals using atomic absorption spectrophotometer. Northwest Sci.,56: 265-267.

Kent, C. 1998. Basic Toxicology. John Wiley Sons.Inc, New York, pp. 402.

Khare, S. and Singh, S. 2002. Histopathological lesions induced by copper sulphate and lead nitrate in the gills of freshwater fish Nandusnandus. J. Ecotoxicol. Environ. Monit., 12: 105-111.

Klavercamp, J. E., MC Donald,W.A., Duncan,D.A. andWagenann, R. 1984. Metallothionein and acclimation to heavy metals in fish, a review. In: Contaminant Effects on Fisheries (Cairns, V. W., Hodson, P. V.,Nriagu, J. O. Eds.), Wiley, New York, pp. 99-113.

Mayer, W., Kretschmer,M., Hoffmann,A. and Harish, G. 1991. Biochemical and histochemical observations on effects of low level heavy metal load (lead, cadmium) in different organ systems of the freshwater crayfish, 
Astacusastacus L. (Crustacea: Decapoda). Ecotoxicol. Environ. Safe., 21: $137-156$

Moore, J.W. and Ramamoorthy, S. 1984. Heavy Metals in Natural Waters: Applied Monitoring and Impact Assessment. Springer Verlag, Tokyo, $1-268$.

Narayanan, K.R., Lyla,P. S. and Ajmal Khan, S. 1997. Pattern of accumulation of heavy metals (mercury, cadmium and zinc) in the mud crab Scylla serrata. J. Ecotoxicol. Environ. Monit., 7: 191-195.

Paul, V.I. and Banerjee, T.K. 1996. Analysis of ammonium sulphate toxicity in the catfish Heteropneustesfossilis using mucocyte indexing. Pol. Arch. Hydrobiol., 43: 111-125.

Paul, V.I. and Banerjee, T.K. 1997. Histopathological changes induced by ambient ammonia (ammonium sulphate) on the opercular linings of the live fish Heteropneustesfossilis (Bloch). Dis. Aquat. Org., 28: 15-161.

Protasowicki, M. andChodyneicki, A. 1992. Bioaccumulation of cadmium in some organs of carp, Cyprinuscarpio L. in case of per os administration. Arch. Pol. Fish., 1: 61-66.

Rajan, M.T. and Banerjee, T.K. 1991. Histopathological changes induced by acute toxicity of mercuric chloride on the epidermis of freshwater catfish Heteropneustesfossilis (Bloch). Ecotoxicol. Environ. Safe., 22: 139-152.

Rema, L.P. and Philip, B. 1997. Accumulation of an essential metal (zinc) and a non-essential metal (mercury) in different tissues of Oreochromismossambicus (Peters). Ind. J. Exp. Biol., 35: 67-69.

Satyanarayanan, D., Rao,I. M. andPrasada Reddy, B.R. 1985. Chemical oceanography of harbor and coastal environment of Visakhapatnam (Bay of Bengal). Part I: Trace metals in water and particulate matter. J. Mar. Sci., 14: 139-146.

Woodling, J. D., Brinkman,S. F. and Horn, B.J. 2001. Non uniform accumulation of cadmium and copper in kidneys of wild brown trout Salmotrutta populations. Arch. Environ. Contam. Toxicol., 40: 381-385. 